\title{
Erratum to: Prenatal exposure to escitalopram and/or stress in rats
}

\section{A prenatal stress model of maternal depression and its treatment}

Chase H. Bourke • Catherine F. Capello •

Swati M. Rogers • Megan L. Yu •

Katherine A. Boss-Williams • Jay M. Weiss •

Zachary N. Stowe $\cdot$ Michael J. Owens

Published online: 10 August 2014

(C) Springer-Verlag Berlin Heidelberg 2014

Erratum to: Psychopharmacology 228 (2): 231-241

DOI 10.1007/s00213-013-3030-z

There was a figure labeling mistake in the original version of this paper: The x-axis units in Fig. 1a should be in hours and not in minutes. Thus, the x-axis should read "Time (h)".

The online version of the original article can be found athttp://dx.doi.org/ 10.1007/s00213-013-3030-z.

C. H. Bourke $\cdot$ C. F. Capello S. M. Rogers $\cdot$ M. L. Yu

K. A. Boss-Williams $\cdot$ J. M. Weiss $\cdot$ M. J. Owens $(\bowtie)$

Laboratory of Neuropsychopharmacology, Department of

Psychiatry and Behavioral Sciences, Emory University, 101

Woodruff Circle, Suite 4000,

Atlanta, GA 30322, USA

e-mail: mowens@emory.edu

\section{Z. N. Stowe}

Department of Psychiatry, Pediatrics and Obstetrics and

Gynecology, University of Arkansas for Medical Sciences, Little

Rock, AR, USA 